\title{
Plutella xylostella (L.) population control in sowings of spring rapeseed using pheromones
}

\author{
Sergey Semerenko, and Nadezhda Bushneva* \\ V.S. Pustovoit All-Russian Research Institute of Oil Crops, 17 Filatova street, 350038, Krasnodar, \\ Russia
}

\begin{abstract}
The diamondback moth Plutella xylostella (Linnaeus, 1758) is a common pest of rapeseed and other crops of Brassicaceae family. Annual yield losses and costs of pest control worldwide are estimated at \$ 4-5 billion. The pest has an increased tendency to develop resistance to insecticides. The use of traps with synthetic sex pheromone is a modern instrumental method of monitoring P. xylostella. The use of the mating disruption method will effectively decrease pest numbers and reduce the application of insecticides. In 2017-2020, we researched the pheromone activity and evaluated the mating disruption method in the sowings of spring rapeseed at V.S. Pustovoit All-Russian Research Institute of Oil Crops (VNIIMK) (Krasnodar). We established that P. xylostella males were caught in traps with all tested dispenser types. The pheromone showed the greatest activity on the foil-film dispenser (F). The mating disruption method effectively decreased $P$. xylostella population in rapeseed sowing; the disruption effect by the end of crop vegetation was high and reached $82.5 \%$.
\end{abstract}

\section{Introduction}

Analysts predict a $30 \%$ increase in global population (up to 9.2 billion people) by the middle of the $21^{\text {st }}$ century, which will increase the demand for food production by $70 \%$ and require further expansion of modern agriculture [1,2]. At the same time, this will contribute the accumulation of insect pests in sowings of agricultural crops, which are currently controlled by spraying insecticides or using genetically modified (GM) crops. However, the insects are rapidly developing resistance. In addition, insecticides and GM crops are prohibited in organic farming $[3,4]$.

There is therefore a real need for new, effective solutions for pest control. Within the concept of Integrated Pest Management (IPM), the use of pheromones is highly effective, environmentally friendly, and safe. It enables early detection of pests quickly and with a sufficiently high degree of reliability. By creating the same pheromones as the insects and releasing them over crop fields, it is possible to disrupt insect mating, thereby inhibiting insect reproduction and thus pest harmfulness. This approach is considered one of the promising ones [5-7].

\footnotetext{
* Corresponding author: naducha74@mail.ru
} 
The cultivation of oil crops is considered to be the most profitable direction in the plant production industry. Rapeseed (Brassica napus L.) is the main oil crop in the Brassicaceae family and is grown all over the world. The seeds of rapeseed are used for the production of edible oil, a source of essential omega- 3 and omega- 6 fatty acids, as well as biological fuel. The meal is high in protein and is a source of fodder for farm animals. In addition, rapeseed is used as a green manure crop to improve the physical properties of the soil and its fertility [8-10].

The diamondback moth Plutella xylostella (Linnaeus, 1758) (Lepidoptera: Plutellidae) is a common polyvoltine insect pest of the crops of the Brassicaceae family. Global yield losses and control costs associated with Plutella xylostella are estimated at about \$ 4-5 billion annually. Pest caterpillars can destroy rapeseed seedlings, damage leaves, flowers, the green outer layer of stems, and the developing seeds in pods, thereby significantly reducing crop yield. The pest has an increased tendency to develop resistance to insecticides because of its high reproductive capacity [11-14].

The strategy for effective control of $P$. xylostella on rapeseed is the timely detection of the pest imago. The use of synthetic sex pheromone traps is one of the least timeconsuming and most modern instrumental methods of monitoring and predicting pest densities. The use of mating disruption, during which pheromones are released in significant quantities in the air of fields, resulting in a male disorientation effect - the inability to detect females and mate - will effectively decrease pest numbers and reduce insecticide use [15-16].

To improve the control of $P$. xylostella on the sowings of spring rapeseed, we studied the activity of a synthetic pheromone in several preparative forms for the timely detection of the pest and the possibility of decreasing its population numbers, using the mating disruption method.

\section{Materials and methods}

The material for writing this article was the results of evaluating the effectiveness under field conditions of a synthetic analog of sex pheromone for $P$. xylostella on different types of dispensers produced by AO "Schelkovo Agrohim" designed to catch insects in traps during monitoring, as well as to decrease the pest populations by mating disruption.

In 2017-2020, we carried out the research at V.S. Pustovoit All-Russian Research Institute of Oil Crops (Krasnodar) on the sowings of spring rapeseed of variety Ruyan. We tested the preparative forms in the experiment to study pheromone activity: rubber dispensers in the form of tubes of two colors (white rubber tube - WRT, red rubber tube - RRT) with a diameter of $5 \mathrm{~mm}$ and length of 7-8 $\mathrm{mm}$, saturated with a solution of pheromone components in hexane by swelling method; foil-film dispenser (F) hermetically sealed multi-layer bags of foil-film $2.5 \times 2.7 \mathrm{~cm}$ in size, containing a solution of pheromone components between the foil-film and inner layers of the film, through which the substances are emitted.

We placed the dispensers in delta traps ( 1 dispenser per trap) and we used standard inserts with Pestifix glue to fix the attracted moths in the traps. Traps were set 10 days before the expected beginning of $P$. xylostella flight at the rate of 3 traps per 1 ha (one in the center of the plot and two at the edges of the plot). Rubber dispensers were replaced after 30 days, while foil-film dispensers were hung out for the whole season without replacement. We tested each type of dispenser in 3 replications, there were 27 traps in total. We conducted the counting daily until the first moths were caught in the pheromone traps, and then once a week.

We evaluated the mating disruption method on a 1 ha plot of spring rapeseed sowing with a manual distribution of 150 rubber tubes. Each dispenser contained $2 \mathrm{mg}$ of 
pheromone, and the total dose per 1 has was $300 \mathrm{mg}$. A sowing area of spring rapeseed of 1 ha without pheromone application was the control. The pheromone traps under record were placed on the experimental and control plots at the rate of 10 pieces per plot. The counting of attracted males was conducted weekly from early May to late July. The disorientation effect was calculated from the number of males attracted by the pheromone traps at the experimental plots compared to the control.

\section{Results and discussion}

During the last ten years, a high infestation of spring rapeseed sowings by $P$. xylostella (about 5-9 specimens/plant) has been observed in the Krasnodar region. The conditions of the region are favorable for the development of two and sometimes three generations of the pest. Visual observations of the time of phytophage emergence in sowing and its quantity often lead to errors because the beginning of imago flight depends significantly on weather conditions. The optimal temperature for the development of the diamondback moth is $10{ }^{\circ} \mathrm{C}$ but it can also develop at $5{ }^{\circ} \mathrm{C}$. The upper temperature limit for moth development is $35-37^{\circ} \mathrm{C}$.

We conducted experiments on studying the pheromone activity for the timely detection of P. xylostella and pheromonitoring in 2017-2018. In 2017, the first moths appeared in spring rapeseed sowings at the end of the last ten days of May, when air temperature reached $17.3{ }^{\circ} \mathrm{C}$ and relative humidity was $64 \%$. At the initial stage of the tests, the number of caught pest imago in traps with F and WRT dispensers was at the same level, and the number with RRT dispenser was the lowest (Table 1).

Table 1. Pheromone activity for Plutella xylostella (L.) on different dispensers, 2017.

\begin{tabular}{|l|c|c|c|c|c|c|c|}
\hline \multirow{2}{*}{ Variant } & \multicolumn{6}{|c|}{ Number of caught male moths, specimens/trap, by recording date } \\
\cline { 2 - 8 } & 27.05 & 03.06 & 11.06 & 18.06 & 25.06 & 02.07 & 11.07 \\
\hline RRT dispenser & 10 & 54 & 73 & 96 & 199 & 182 & 83 \\
\hline WRT dispenser & 18 & 44 & 40 & 37 & 46 & 32 & 25 \\
\hline F dispenser & 20 & 82 & 114 & 121 & 212 & 170 & 97 \\
\hline
\end{tabular}

Subsequently, the ratio of caught males varied depending on the type of dispenser. The number of moths in traps with RRT dispensers increased from the first ten days of June and did not decrease by the end of 30 days, indicating pheromone activity on this dispenser. In traps with WRT dispensers the number of male diamondback moths gradually decreased, and by the end of the pheromone activity period, the average number of specimens was 37 . After replacing the dispenser, there was a slight increase in the number of caught pests, but it was minimal in comparison with other variants. Throughout the season, the pheromone on foil-film dispenser (F) showed the highest activity, with the number of caught moths varying from 82 to 212 specimens/trap, depending on the date of recording (Fig. 1). 

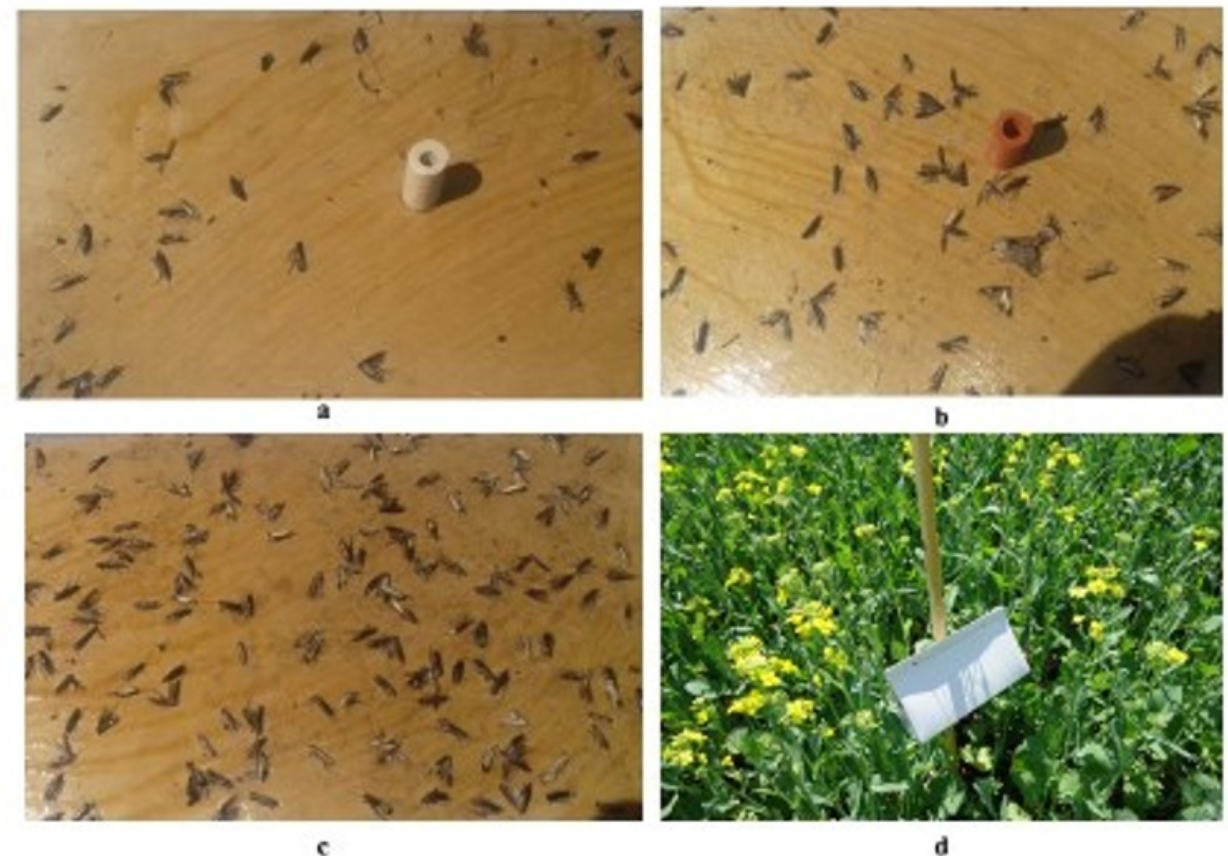

Fig. 1. Activity of pheromone of Plutella xylostella (L.) on different dispensers in traps: a) white rubber tube (WRT); b) red rubber tube (RRT); c) foil-film (F); d) traps appearance.

The recordings conducted in 2018 showed that $P$. xylostella moths began flying in spring rapeseed sowing from the second ten-day period of May. Nevertheless, the number of the diamondback moth imago was lower than in the previous year, which is explained by less favorable conditions for reproduction and development of the insect pest. Thus, in 2017, the sum of precipitation during the research period was $309.6 \mathrm{~mm}$, while in 2018 it was half as much and was at the level of $196.8 \mathrm{~mm}$. In 2017, the maximum air temperature by months was: May - 16-19 c; June $-27-32{ }^{\circ} \mathrm{C}$; and July $-30-32{ }^{\circ} \mathrm{C}$. In 2018 , the indicators for the same period were higher: $27-33^{\circ} \mathrm{C} ; 40-41{ }^{\circ} \mathrm{C}$; and $37-40{ }^{\circ} \mathrm{C}$, respectively, which are higher than the upper temperature values of diamondback moth development.

The second testing of pheromone activity on different types of dispensers confirmed the preliminary data obtained the year before. The best catching dynamics of male diamondback moths were recorded in traps with F dispensers, the effectiveness of traps with WRT dispensers was lower (Table 2).

Table 2. Pheromone activity for Plutella xylostella (L.) on different dispensers, 2018.

\begin{tabular}{|l|c|c|c|c|c|c|c|}
\hline \multirow{2}{*}{ Variant } & \multicolumn{6}{|c|}{ Number of caught male moths, specimens/trap, by recording date } \\
\cline { 2 - 9 } & 18.05 & 25.05 & 02.06 & 09.06 & 16.06 & 23.06 & 02.07 \\
\hline RRT dispenser & 8 & 10 & 23 & 48 & 30 & 60 & 7 \\
\hline WRT dispenser & 5 & 10 & 15 & 30 & 20 & 33 & 4 \\
\hline F dispenser & 14 & 20 & 30 & 80 & 60 & 95 & 7 \\
\hline
\end{tabular}


The results show that all tested dispensers can be used to detect $P$. xylostella in rapeseed sowings in time. Monitoring of the pest is better carried out with the pheromone on F dispenser as its activity remained high throughout the period of use or on the RRT dispenser.

Experiments on $P$. xylostella mating disruption were carried out in 2019-2020. The effectiveness of the mating disruption method with the application of pheromone to the station was evaluated by the almost complete absence of male moths attracted to the pheromone traps in the experiment.

The first moths were caught in traps located on the control plot from the first ten days of May and their number reached an average of 32.0 specimens/trap. Later, the number of pests increased and reached its maximum at the beginning of the first ten days of July with 112.6 specimens/trap. In the experiment, single specimens of the pest appeared at the end of the first ten days of June, their number gradually increased and reached its maximum in the middle of the second ten-day period of July. The resulting mating disruption effect was high (over $60 \%$ ), and in the period from the first to the third tenday period of May it reached the maximum (100\%) (Table 3 ).

Table 3. Biological effectiveness of mating disruption of Plutella xylostella (L.) by pheromones, 2019-2020.

\begin{tabular}{|c|c|c|c|}
\hline \multirow{2}{*}{ Date of recording } & \multicolumn{2}{|c|}{ Number of insects, specimens/trap } & \multirow{2}{*}{ Effect of mating disruption, \% } \\
\cline { 2 - 3 } & control & experiment & 100 \\
\hline 04.05 & 32.0 & 0.0 & 100 \\
\hline 10.05 & 37.0 & 0.0 & 100 \\
\hline 25.05 & 49.0 & 0.0 & 99.6 \\
\hline 08.06 & 93.1 & 0.4 & 98.5 \\
\hline 15.06 & 61.5 & 0.9 & 98.7 \\
\hline 20.06 & 100.1 & 1.3 & 98.0 \\
\hline 01.07 & 112.6 & 2.2 & 92.0 \\
\hline 07.07 & 101.0 & 8.0 & 86.5 \\
\hline 14.07 & 83.0 & 11.2 & 82.5 \\
\hline 20.07 & 54.4 & 9.5 & \\
\hline
\end{tabular}

\section{Conclusions}

Tests of the synthetic pheromone revealed that P. xylostella males were caught in traps with all tested types of dispensers. The pheromone showed the highest activity on the foil-film dispenser (F). The mating disruption method effectively decreased the number of $P$. xylostella males in the rapeseed sowing; the effect of disruption by the end of the crop vegetation was high and reached $82.5 \%$. 


\section{References}

1. B. Lanz, S. Dietz, T. Swansone, Ecological Economics 144, 260 (2018)

2. V. Kvakkestad, A. Sundbye, G.I. Klingena Environmental Science \& Policy, 106, 115 (2020)

3. K. Petkevicius, Ch. Löfstedt, I. Borodina Current Opinion in Biotechnology, 65, 259 (2020)

4. M. Nasra, J.J. Sendi, S. Moharramipour, A. Zibaee Journal of the Saudi Society of Agricultural Sciences, 16, 184 (2017)

5. C. Holkenbrink, B.-J. Ding, H.-L. Wang, M.I. Dam, K. Petkevicius, K.R. Kildegaard, L. Wenning, Ch. Sinkwitz, B. Lorántfy, E. Koutsoumpeli, L. França, M. Pires, C. Bernardi, W. Urrutia, A. Mafra-Neto, B. S. Ferreira, D. Raptopoulos, M. Konstantopoulou ... I. Borodina Metabolic Engineering, 62, 312 (2020)

6. J.K. Yuvara, M.N. Andersson, J.A. Corcoran, O. Anderbrant, Ch. Löfstedt Insect Biochemistry and Molecular Biology, 100, 39 (2018)

7. M. Sumedrea, F.-C. Marin., M. Calinescu, D. Sumed, A. Iorgur Agriculture and Agricultural Science Procedia, 6, 171 (2015)

8. E. Woźniak, E. Waszkowska, T. Zimny, S. Sowa and T. Twardowski Front. Plant Sci. 10, 1423 (2019)

9. B. Zhao, R. Xu, Ma. Fengfeng, Y. Li, L. Wang J. of Environmental Management, 184, 569 (2016)

10. Z. Yang, M. Xu, S. Zheng, J. Nie, J. Gao, Y. Liao and J. J. Xie of Integrative Agriculture, 11, 655 (2012)

11. W. Jaleel, Sh. Saeed, M.N. Naqqash, U. Sial, M. Ali, S.M .Zaka, Z.M. Sarwar, M. Ishtiaq, M.A., Qayyum, Q.U. Aine, A. Anwar, M. Sarmad, R. Azad, M. Latif, A.Furqan., I. Waqar., K.A. Khan, H.A. Ghramh Saudi Journal of Biological Sciences, 27, 1 (2020)

12. M. P. Zaluck, Sh. Asad, R. Silva, D. Adamson, Shu-L. Sheng, M. J. Furlong Economic Entomology, 105, 115 (2012)

13. S.E. Squires, L. Hermanutz, P.L. Dixon Biological Conservation, 142, 203 (2009)

14. S. Saeed, W. Jaleel, M.N. Naqqash, Q. Saeed., S.M. Zaka, Z.M. Sarwar, M. Ishtiaq, M.A Qayyum., M.U. Sial, Qurat-Ul-Aine, M. Batool, Kh. AliKhan, H.A. Ghramh, M. Hafeez, M.J. Ansari, G.K. Sharma. Journal of Biological Sciences, 26, 1661 (2019)

15. Ch.E. Miluch, L.M. Dosdall, M. L. Evenden Crop Protection, 45, 89 (2013)

16. S. Tewari, T.C. Leskey, A.L. Nielsen, J.C. Piñero, C.R. Rodriguez-Saona Integrated Pest Management, 141 (2014) 